\title{
Análisis crítico de los discursos audiovisuales sobre violencia de género: estudio comparado de caso
}

\author{
Belén Zurbano Berenguer \\ Universidad de Sevilla \\ bzurbano@us.es \\ Irene Higinia LIBERIA VAYÁ \\ Universidad de Sevilla \\ ireneliberia@gmail.com
}

Recibido: 04/12/2012

Aceptado: 09/09/2013

\begin{abstract}
Resumen
Los formatos audiovisuales se han convertido, por su relevancia y liderazgo, en los principales representantes de los discursos sociales y mediáticos actuales, y por ello, en foco central de las reflexiones teóricas sobre los discursos de los medios de comunicación. En este contexto y si atendemos a los cuestionamientos deontológicos de los entes comunicativos públicos, la información audiovisual sobre violencia de género se vuelve un asunto ineludible. Los media son la principal fuente de conocimiento de esta cuestión para la ciudadanía y uno de los agentes más potentes para su erradicación. Por ello y para continuar una senda menos estudiada que la de la representación en la prensa impresa, esta comunicación pretende abordar, mediante un análisis comparativo de cuatro estudios de caso, los modos de narración, conceptualización y transmisión de este problema en los informativos televisivos.

Palabras clave: Medios de comunicación, violencia de género, violencia doméstica, televisión

\section{A critical analysis of audiovisual discourses about gender-based violence: a comparative case study}

\begin{abstract}
Audiovisual formats have become, because of their relevance and leadership, the main representatives of social and media discourse today, and therefore they are the central focus of theoretical reflections on the discourse of the media. In this context, and if we look at the ethical questions in the field of public media entities, audiovisual information on gender-based violence becomes an unavoidable issue. The media are the main source of knowledge of this problem for citizens and one of the most powerful agents for its eradication. Therefore, and to complete previous studies based on written press, this paper aims to provide an overview and a descriptive interpretative analysis of the modes of narration, conceptualization and transmission of this serious problem in the TV news by means of a comparative analysis of four case studies.
\end{abstract}

Keywords: Media, gender-based violence, domestic violence, television

\section{Referencia normalizada}

ZURBANO BERENGUER, Belén y LIBERIA VAYÁ, Irene H. (2013): “Análisis crítico de los discursos audiovisuales sobre violencia de género: estudio comparado de caso". Estudios sobre el Mensaje Periodístico. Vol. 19, Núm. 2 (julio-diciembre), págs.: 921-939. Madrid, Servicio de Publicaciones de la Universidad Complutense.

Sumario: 1. Introducción. 2. Objetivos e hipótesis. 3. Método. 4. Resultados de investigación; 4.1. Análisis: el relato televisivo o cómo matan los hombres a las mujeres; 4.1.1. Telecinco: la ineficacia de las medidas legales; 4.1.2. Cuatro: "agujeros" en la lucha contra la violencia de género; 4.1.3. Televisión Española: en primer lugar el agresor; 4.1.4. Canal Sur: escueto e impersonal; 4.1.5. Apuntes finales sobre el análisis; 4.2. El seguimiento de las recomendaciones. 5. Discusión y conclusiones. 6. Referencias. 


\section{Introducción}

La violencia de género es, aún hoy, una funesta realidad -nacional e internacionalque se cobra la vida de miles de mujeres cada año. En España, los últimos informes estadísticos del ya extinto Ministerio de Igualdad ${ }^{1}$ revelan cómo se siguen sucediendo estas muertes violentas y ni siquiera puede hablarse de una mejoría -numérica- a pesar de los esfuerzos institucionales para la erradicación de la violencia contra la mujer, así como para su protección y la de los menores a su cargo.

Ante este problema, los medios de comunicación poseen un indudable papel en la sociedad, a la cual se deben por su función social primigenia:

Los medios de comunicación tienen una responsabilidad esencial en la potenciación de estos cambios [cambio en los valores tradicionales, construcción de nuevos referentes, lucha por la igualdad] [...] y ello pasa en primera instancia por una aproximación profesional a las noticias sobre violencia de género para romper con las referencias que vienen a justificarla como parte de una anormalidad irreal, y para representar los casos como piezas de todo un engranaje que cobra sentido a través de su perpetuación (Lorente Acosta, 2009:17).

En el III Informe Internacional Violencia contra la mujer en las relaciones de pareja del Centro Reina Sofia (Sanmartín et al., 2010), Sanmartín incide también en lo que actualmente se contempla como uno de los grandes riesgos de la información sobre violencia de género: el peligro de imitación o la inducción a la insensibilización por repetición del mensaje, y, sobre todo, la capacidad mediática para sesgar la visión que se tiene sobre la realidad ${ }^{2}$. En televisión, el enfoque de las noticias referidas a violencia de género acarrea efectos como los que se señalan a continuación:

The presence of IPV ${ }^{3}$ in television news reports would seem to increase the possibility of death from this cause by between $32 \%$ and $42 \%$. News reports which focus exclusively on transmitting information about deaths from this cause would also appear to increase the possibility of death by between $28 \%$ and $32 \%$. The opposite effect was observed when comparing news items about deaths with those about measures (relating to laws, declarations and interviews with politicians and key figures in the field of violence against women or public acts condemning this type of crime) or other IPV crimes. (Vives Cases, Torrubiano Domínguez y Álvarez- Dardet, 2009: 594).

La importancia de lo expuesto anteriormente deja a los medios de comunicación situados en el epicentro de una responsabilidad difícilmente eludible. En este con-

1 En el último informe ejecutivo publicado en julio de 2010, III Informe Anual del Observatorio Estatal de Violencia sobre la Mujer se ofrece una panorámica de las muertes sucedidas entre los años 2003 y 2009 que no refleja una tendencia a la baja de estos homicidios sino "persistencia de los crímenes y variabilidad en las tasas". (Ministerio de Sanidad, Política Social e Igualdad, 2010).

2 En cuanto a los efectos del discurso mediático, Carmona Vergara establece éstos: imitación o efecto eco, efecto narcotizante, efecto de distanciamiento de la audiencia, efecto atemorizante en las víctimas, efectos en los agresores, efectos de distanciamiento con la realidad social, efecto de desconfianza del ciudadano en la justicia y efectos sobre los profesionales de los juzgados.

3 Intimate partner violence (terminología utilizada por los autores del artículo). 
texto, la comunicación televisada cobra una especial relevancia por ser el formato periodístico que mayor penetración tiene en la sociedad (Estudio General de Medios, 2011), y porque se trata de la principal fuente de información y conocimiento acerca de este fenómeno (Ministerio de Sanidad, Política Social e Igualdad, 2011).

Desde el ámbito académico, Aimé Vega define así la responsabilidad de la televisión en la realización de los derechos humanos de las mujeres:

Los medios de comunicación han sido señalados como una institución que tiene la responsabilidad de erradicar la violencia contra las mujeres y, en consecuencia, contribuir a la realización de los derechos humanos de éstas. Al constituirse como una fuente de educación -formal e informal- para la sociedad, al lado de la familia y de la escuela, tienen una tarea central en la búsqueda de soluciones (Vega Montiel, 2010).

Llegados a este punto y teniendo en cuenta la gran influencia del discurso televisivo en el tratamiento mediático en general y en la conformación de la conciencia social con respecto al problema de la violencia de género, hemos circunscrito nuestro estudio a un ámbito muy concreto dentro del discurso televisivo: el análisis de noticias insertas en informativos.

\section{Objetivos e hipótesis}

Los objetivos que nos planteamos al abordar este trabajo son los siguientes:

1) Reconocer, cuantificar y analizar las formas en que cuatro de las principales cadenas de televisión españolas abordan el problema de la violencia de género a nivel terminológico.

2) Estudiar los principales rasgos de las noticias de violencia de género a fin de sistematizar una caracterización del propio concepto tanto a nivel formal como de contenido en los medios estudiados.

3) Comparar la representación de la violencia de género en estos medios con las principales recomendaciones estilístico-deontológicas a fin de comprobar si no la eficacia de la autorregulación, sí la vigencia de estas normas en la actualidad.

La hipótesis de partida está ligada a la premisa de que los medios no llevan a cabo un tratamiento riguroso y profesional de las informaciones de violencia de género, a pesar de que dicho tratamiento está regulado por el legislador ${ }^{4}$ (y por otros documen-

${ }^{4}$ La importancia que poseen los medios informativos en cuanto a la representación y transmisión de la violencia de género ha sido valorada por el legislador en la Ley Orgánica 1/2004, de 28 de diciembre, de Medidas de Protección Integral contra la Violencia de Género, en la que insta a los mismos a cumplir su compromiso primigenio con la sociedad, estableciendo en parte de su articulado que "fomentarán la protección y salvaguarda de la igualdad entre hombre y mujer, evitando toda discriminación entre ellos. La difusión de informaciones relativas a la violencia sobre la mujer garantizará, con la correspondiente objetividad informativa, la defensa de los derechos humanos, la libertad y dignidad de las mujeres víctimas de violencia y de sus hijos. En particular, se tendrá especial cuidado en el tratamiento gráfico de las informaciones" (Boletín Oficial del Estado, 2004). 
tos normativos y autorregulatorios), que entiende que el discurso mediático es fuente esencial de promoción del cambio y la sensibilidad social. Además, esta falta de rigor en el tratamiento noticioso redunda en una configuración defectuosa -por fragmentada, dispersa y carente de un uso terminológico claro y consensuado- del propio concepto de violencia de género.

\section{Método}

Para llevar a cabo nuestros objetivos hemos realizado un análisis comparativo de cuatro piezas noticiosas con un mismo referente: el asesinato, el día 6 de diciembre de 2010, de una mujer de 25 años en la ciudad de Barakaldo (Vizcaya). Todas las noticias se corresponden con el telediario de la primera edición. Entendemos estas noticias como los relatos periodísticos caracterizados por: a) informar detalladamente sobre el hecho de actualidad; b) poseer los antecedentes y consecuencias del hecho de actualidad con un fin explicativo de cara al público; c) comparar con casos similares que han ocurrido en ocasiones anteriores en otras partes del mundo y las medidas que se han aplicado para dar solución a la problemática generada por estos hechos (AA.VV., 2005).

Las piezas se corresponden con cuatro noticias emitidas en las siguientes cadenas de televisión: Cuatro, Telecinco, Televisión Española y Televisión Andaluza. Es decir, hemos seleccionado cadenas tanto públicas como privadas y todas existentes antes del "apagón analógico", por lo tanto, con una cierta trayectoria audiovisual a sus espaldas -incluida la más reciente Cuatro-.

En cuanto a lo que en este trabajo consideramos noticias que tratan la violencia de género, nos centraremos en la consecuencia final y más trágica de dicha violencia: la muerte. Esta elección atiende a diversas razones: es la forma de violencia con una mayor cobertura en televisión, es una situación dramática en la que hay que tener un cuidado más especial ya que nos encontramos ante la indefensión más absoluta de la fallecida y de su entorno familiar, y, además, está claramente identificada social y mediáticamente como un acto de violencia de géneros.

Para llevar a cabo nuestro objetivo tomaremos como referencia los preceptos del análisis de contenido, definido por Krippendorf (1980) como una técnica de investigación para hacer inferencias reproducibles y válidas de los datos a su contexto, y por Bardin como un "conjunto de instrumentos metodológicos cada vez más perfectos y en constante mejora, aplicados a discursos (contenidos y continente) extremadamente diversificados" (1986: 7). Este instrumento constituye un procedimiento singular de las Ciencias Sociales (cuantitativo y cualitativo) para la recogida y el procesamiento de datos, que persigue la búsqueda de inferencias, la verificación o refutación de hipótesis y el establecimiento de procesos o modelos comunicativos. Por esta razón creemos ha-

${ }^{5}$ Las autoras partimos del presupuesto de que los medios de comunicación no siempre conceptualizan las diferentes formas de agresión a la mujer como formas de violencia de género, sino que las reducen al ámbito de los sucesos, presentando determinados actos aisladamente y no como violencia de género; esto es muy común en los casos de agresión sexual. 
llar en ellos el marco metodológico idóneo en el que sustentar nuestra mirada crítica sobre un asunto en el que los expertos ya vislumbran visos de desviación deontológica.

Nuestro trabajo consta de dos fases diferenciadas: en primer lugar, el análisis de la noticia conforme a los criterios de análisis diseñados ex profeso (se detallará más adelante); en segundo lugar, la evaluación deontológica de la pieza, para lo cual hemos tomado como referente lo que a nuestro parecer constituye el principal y más completo decálogo de recomendaciones sobre el tratamiento informativo audiovisual de la violencia de género: el Manual de Urgencia llevado a cabo por el Instituto Oficial de Radio y Televisión (IORTV) en 2002, dentro del estudio Mujer, violencia y medios de comunicación ${ }^{6}$.

Para llevar a cabo el análisis en un plano tanto formal como de contenido, nos basaremos en una herramienta cercana a la ficha de análisis que, sin serlo exactamente, puede actuar como guía o marco de focalización de la atención en el visionado y trabajo posterior. En ella se atiende a diferentes elementos encuadrados en dos ámbitos: criterios formales (entre los que se han tenido en cuenta: la duración de la pieza, el criterio de ordenación de la información, el formato de la pieza, el tipo de planos predominantes o los recursos expresivos, entre otros) y contenido (estructura de la información, identificación del emisor principal, foco informativo principal, valor informativo de los diferentes elementos y fórmulas terminológicas, entre otros).

\section{Resultados de investigación}

\subsection{Análisis: el relato televisivo o cómo matan los hombres a las mujeres}

A continuación, aportamos los resultados de los análisis realizados sobre cada una de las piezas informativas escogidas. Dichos análisis se han llevado a cabo de manera individual y ordenada, incluyendo tanto descripciones como comentarios y valoraciones derivados de nuestra interpretación, conscientes de que ésta es una parte imprescindible del ejercicio analítico. Con el fin de facilitar la búsqueda de las noticias y titulares objeto de nuestro estudio en los telediarios completos, aportamos el siguiente cuadro informativo:

\subsubsection{Telecinco: la ineficacia de las medidas legales}

La primera de las noticias seleccionadas, emitida en los informativos de la segunda edición de Telecinco, tiene una duración de 2:54 minutos y un formato que podemos resumir así: colas + intro + conexión en directo + entradilla en directo + VTR. Se trata de una información anunciada ya en titulares, en el

\begin{tabular}{|c|r|r|}
\hline \multicolumn{3}{|c|}{ Cuadro 1: Temporalización de las piezas } \\
informativas \\
\hline Cadena & Titular noticia & \multicolumn{1}{|c|}{ Noticia } \\
\hline Telecinco & 01.04 & 25.46 \\
\hline Cuatro & 07.31 & 30.11 \\
\hline TVE & -- & 18.53 \\
\hline Canal Sur & 5.29 & 35.34 \\
\hline
\end{tabular}
minuto 1.04 .

${ }^{6}$ Las orientaciones planteadas en este manual fueron asumidas por Televisión Española, las dos principales cadenas privadas en los tiempos del analógico (Antena 3 y Telecinco) y todas las cadenas públicas autonómicas, excepto la catalana y la vasca (López, P., 2005). 
Dicha pieza se sitúa en la parte final del informativo pero presenta un titular retrasado en el que se puede intuir ya el foco principal de la noticia: "La víctima había denunciado al agresor que tenía orden de alejamiento". A este respecto, en los primeros sumarios del informativo también se alude al mismo hecho con un rótulo que dice: "Ni con orden de alejamiento".

En cuanto al tipo de imágenes utilizadas, se trata en su totalidad de imágenes propias y circunscritas al lugar del acontecimiento. Éstas se centran fundamentalmente en tres ámbitos: los restos de la agresión (sangre, precintos policiales, cuerpo sin vida, etc.), los servicios de emergencia (personal médico, forenses) y personas del entorno de la víctima (testimonios). Estas últimas, que aparecen en su mayoría como totales, son todas mujeres y ninguna está identificada mediante un rótulo. Concretamente, se trata de una vecina que llamó a emergencias, de la regente de un videoclub donde uno de los agredidos pidió ayuda, de una joven que también fue testigo de esta demanda de ayuda, y de cuatro mujeres situadas frente a portales de la calle o puertas de viviendas del edificio que aparece identificado como el lugar de los hechos.

Todos los testimonios que construyen el relato de los acontecimientos son fácilmente vinculables al entorno vecinal de la víctima, hecho que parece legitimarlos. En concreto, hay uno de ellos que llama poderosamente nuestra atención, es el de una mujer que pone palabras a la supuesta motivación del agresor: "habrá pensado: mira, si no es para mí...". Este final de frase que queda en el aire es acompañado por un gesto con la cabeza que nos sugiere: “... pues para nadie”. Así, el relato noticioso parece hacer suya de alguna forma esta explicación, aunque nunca abiertamente. A este respecto, consideramos que el discurso periodístico no debería esgrimir nunca una causa de celos para hablar de las razones de un crimen de violencia de género.

Por lo que se refiere a los tipos de plano, movimientos de cámara y transiciones, debemos señalar que predominan los planos identificativos (cortos y medios en las declaraciones y en el interior del edificio; más generales en el exterior), las transiciones por corte y los planos fijos. Aunque muchos de éstos están realizados con cámara al hombro, por lo tanto, hay un movimiento ligero en ocasiones y más marcado otras veces. También encontramos panorámicas para mostrar el lugar de los hechos y determinados detalles, así como un zoom de los restos de sangre en el suelo del ascensor que se abre para contextualizar lo que estamos viendo. Asimismo, nos llama la atención el plano con el que se inicia el vídeo: un contrapicado de dos allegadas a la víctima abrazándose mientras lloran, cosa que magnifica la situación y apela al sentimentalismo.

Respecto a la secuencialidad de las imágenes y de la información, es de tipo cronológico. El VTR comienza con una introducción donde se anticipa el desenlace, es decir, la muerte de la mujer, seguida de una recreación de lo ocurrido en estricto orden temporal. Esta segunda parte tiene una mayor duración y, por lo tanto, mayor importancia.

La noticia que estamos tratando podría definirse como una hard new a mitad de camino entre una información simple (ya que se ciñe al relato de un solo hecho sin relacionarlo con otros) y una información de interés humano, tanto por el interés social de su contenido como por el tipo de relato que se hace. Es, asimismo, una "noticia ilus- 
trada con imágenes", ya que en ella no se muestra de manera directa aquello de lo que se informa (el asesinato no está grabado), pero sí que se cuentan los hechos con imágenes reales, testimonios y elementos relacionados directamente con el acontecimiento.

En cuanto al tono, prima la seriedad, aunque aderezada con la pasión del presentador de los informativos, David Cantero, que cuenta los hechos con un marcado sentimentalismo, otorgado sobre todo por el uso del nombre propio de las víctimas. En referencia al estilo, distinguimos el de Cantero -más pasional- del de Asier Bailez, el periodista autor del VTR. El primero insiste sobre todo en el foco de interés de la noticia: la inoperancia de las medidas de protección (en el minuto 25:57 dice: "de poco le sirvió a Cristina la denuncia que puso hace un mes contra su presunto asesino y la orden de alejamiento que había dictado un juzgado"). Por su parte, Bailez parece sostener un discurso más oficial y menos apasionado, con una entonación más rutinaria y suave. El tono del VTR se mueve entre la pretendida objetividad del relato cronológico de los hechos y los matices cercanos y más sentimentales otorgados por los testimonios.

La estructura de la pieza es la siguiente:

- [Colas] Se inicia la noticia con la frase: "Es la víctima número 67 de la violencia machista" y se presentan las claves de la información: una mujer está muerta, su novio ha sido herido, existía una orden de alejamiento contra el agresor y ésta sirvió "para poco".

- [Plató: introducción del presentador] Se dice que el agresor ya está detenido y se repite que tenía orden de alejamiento.

- [Conexión en directo] Mediante Multipantalla. Se anuncia una concentración de condena y se conecta con el periodista en Vizcaya.

- [Entradilla en directo] Se dan los detalles sobre la concentración de repulsa.

- Se informa de un modo algo especial que "el ayuntamiento de Barakaldo había ofrecido a la víctima la posibilidad de residir en un piso de acogida para evitar el acoso, pero ella lo rechazó porque quería seguir viviendo con su padre" (26:35).

- Se incide en las denuncias contra el agresor y en la orden de alejamiento.

- [VTR] Se hace alusión a la situación de drama que viven amigos y familiares.

- Tres totales apelan a la situación de desgracia que se vive.

- Comienza el relato cronológico con un "al parecer Cristina estaba..." y se cubre con imágenes de sangre, del trabajo de los forenses y del bloque de pisos donde sucedieron los hechos. Se relata el acontecimiento intercalando testimonios que valoran lo ocurrido.

- Finaliza el relato con la frase "el presunto agresor ya está detenido", mientras la imágenes nos muestran a varios miembros de la Ertzaintza de espaldas.

En resumen, podemos deducir que el centro de atención de la noticia es la orden de alejamiento y su ineficacia, ya que aparece en los momentos clave de la pieza. En cuanto al emisor principal, se trata del presentador del informativo, David Cantero, quien aporta las claves principales de la noticia y el tono más contundente. Además, 
podemos decir que estamos ante una pieza de alto valor informativo, aunque de una duración un tanto sobredimensionada si atendemos a la limitada cantidad de datos que ofrece (nunca en referencia a la magnitud del problema que trata). Por último, en cuanto a la terminología y la conceptualización, se utiliza indistintamente "violencia machista" y "violencia doméstica", cosa que consideramos un error conceptual de base:

The terms "family violence" and "domestic violence" will not be used to denote battering because these terms obscure the relationship between gender and power by failing to identify the perpetrators and victims [...] Suzann Pharr (1991) has addressed the problem of terminology by suggesting the use of "sexist violence" when referring to the various forms of violence against women [...] The term "sexist violence" underscores the institutional and social nature of this violence, placing it within the context of misogyny, patriarchy, and male supremacy (Marian Meyers, 1997).

\subsubsection{Cuatro: "agujeros" en la lucha contra la violencia de género}

Tenemos un anticipo de la noticia en el tiempo de titulares (5: 14): "Nuevo caso de violencia de género". Este sumario, tras una presentación en plató, se abre con el testimonio de una amiga de la víctima, al que sigue una serie de planos tomados en el lugar de los hechos mientras el presentador narra los datos básicos del acontecimiento. Hay un rótulo que hace hincapié en el arresto del culpable: "Asesino detenido". Consideramos que este titular está dotado de un gran contenido emocional, no sólo por la calificación de los hechos como "asesinato", sino por su situación privilegiada en titulares y por el colchón musical que acompaña a esta pequeña pieza.

La noticia propiamente dicha inaugura un bloque que podríamos denominar "Sociedad" (minuto 28:54 del informativo tras una cortinilla) y tiene la siguiente estructura: total + colas + presentación en plató + VTR + cierre del presentador en plató. La duración es de 2:02 minutos, sin embargo, en esta ocasión no la consideramos sobredimensionada, puesto que ofrece más datos que la noticia anterior.

En cuanto a las imágenes, también son todas propias y ligadas directamente al suceso trágico. Muchas de ellas son prácticamente las mismas de la pieza de Telecinco. Predominan los primeros planos relacionados sobre todo con la sangre y los rostros de los presentes en el lugar del acontecimiento, y los planos medios que muestran actividad (trabajo de los forenses, gente que va y viene, etc.). Así, la información en este caso también está ligada al suceso en sí y no al macrotema de la violencia de género. En este sentido, las imágenes nos presentan un hecho que podría ser un suceso luctuoso cualquiera.

Por lo que se refiere a los testimonios, aparte del que veíamos en el sumario, aparecen dos más en el VTR con formato de totales. Uno de ellos se repite en dos ocasiones: se trata de una mujer que relata lo que la pareja actual de la víctima gritaba al salir del edificio para pedir ayuda tras ser agredido. Dada la alta carga dramática del testimonio, podemos hablar de una cierta inclinación al sentimentalismo, quizá como estrategia para acercar el drama a la sociedad. Respecto al segundo total, se corresponde con las declaraciones de una mujer que afirma que la víctima era "muy buena chica". Así, este testimonio viene a confirmar la importante carga de emociones para introducir al espectador en lo sucedido y sensibilizarlo, y también para crear una es- 
pecie de aura de bondad en torno a la mujer asesinada, que además de ser víctima, era joven y era "muy buena".

En esta noticia, todas las personas que dan su testimonio vuelven a ser mujeres, y ninguna de ellas es identificada mediante rótulos. En cuanto al tipo de información ofrecida, aunque los datos principales coinciden, aquí se dan informaciones generales acerca de la violencia de género en España durante el 2010.

Si nos centramos ahora en cuestiones formales, comprobamos que predominan los planos cortos y medios que identifican el lugar de los hechos y los restos del crimen, así como los trabajos realizados por forenses y policía, y las reacciones de los allegados a la víctima. Las transiciones se hacen por corte, y hay alguna pequeña panorámica y zooms muy bruscos que, junto a los movimientos de algunos planos tomados con cámara al hombro, dan la sensación de instantaneidad, de estar recibiendo la noticia casi al mismo tiempo que se ha producido. Encontramos más planos de recurso que en el caso anterior porque el VTR es más largo. En cuanto a la secuencialidad, es de tipo lógico, ya que la pieza está guiada por las argumentaciones del informador.

Estamos ante una noticia "dura" que se incluye dentro de un ámbito considerado un problema social e institucionalmente "pendiente". También es "simple" porque se centra en el caso concreto de la víctima 67 de violencia de género, y "de interés humano" por su modo de elaboración. Como la de Telecinco, es una pieza "ilustrada con imágenes", ya que éstas identifican y presentan lo ocurrido sin haberlo filmado directamente.

Por lo que respecta al tono, podemos decir que está dramatizado, sobre todo si hablamos de la locución del presentador del informativo, que baja ostensiblemente la voz en determinados pasajes y narra de manera lenta y parsimoniosa, casi doliente. En su relato encontramos términos y expresiones como "asesinato", "crimen", "Cristina" (nombre propio de la víctima), "tan sólo 25 años", etc. Asimismo, la personalización de la información (no es sólo una víctima, es Cristina de 25 años) redunda en la emocionalización del espectador, aunque sea con un fin sensibilizador.

Por otra parte, el texto locutado durante las colas presenta una construcción redaccional compleja: "un chico pide ayuda porque es apuñalado y matan a su novia; el agresor era el ex novio de ella". Esto se hace únicamente para primar las declaraciones abominablemente dramáticas que abren la noticia. Además, también queremos destacar el fallo que comete el presentador al afirmar que la mujer "ha muerto" y al decir su edad en presente ("tiene 25 años").

Estructura en la que se presenta la información:

- [Total] Una testigo que reproduce la petición de ayuda del novio agredido: "por favor, por favor, ayudadme, me estoy muriendo, me han apuñalado, la están matando a ella...".

- [Colas] Comienza la locución: "Es lo que gritaba el novio de la última víctima de violencia de género [...] después de que anoche un joven le apuñalase a él y matara a su novia. Era la ex pareja de ella. La chica ha fallecido. Tiene (sic) 25 años". Mientras duran las colas se nos muestra en un rótulo el teléfono de atención al maltrato y el titular "la llamada no aparece en la factura".

- [Plató: presentador] El presentador aporta la principal clave de análisis: "los agujeros en la lucha contra la violencia de género". Insiste en el hecho de que 
la víctima había denunciado y poseía una orden de alejamiento. Se introduce el dato de que había sido atendida hasta 3 veces en el Área de Igualdad de Barakaldo.

- Tras el presentador vemos un plasma con una imagen del teléfono contra los malos tratos.

- Nuevamente se recurre al lamento: "pese a ello ha ocurrido otra vez, un nuevo crimen".

- [VTR] Comienzan a describirse los hechos en orden cronológico inverso.

- Se ofrece el segundo testimonio de la pieza que señala que Cristina era "buena chica".

- Se contextualiza este nuevo caso de violencia de género al indicar el porcentaje del total de mujeres asesinadas durante el 2010 que habían denunciado y el de las que tenían medidas en vigor contra sus agresores.

- [Plató: cierre] El presentador cierra la noticia "hilando" en su discurso "la asignatura pendiente" de la violencia de género con la "asignatura pendiente" de la educación en España, aludiendo a la noticia siguiente.

El foco informativo cabe establecerlo nuevamente en la falta de eficiencia de las medidas judiciales, al repetirse dicho ítem temático en varias ocasiones y durante los momentos clave de la información. Aunque hemos de destacar el hecho de que, en esta ocasión, el titular que aparece en un rótulo de las colas se adscribe a la temática general de la violencia de género, sin hacer alusión directamente a la cuestión de las medidas ineficaces: "Teléfono contra el maltrato 016. La llamada no aparece en la factura". Se trata de una noticia con un alto valor informativo en la que se responden a las principales $w$, y que utiliza siempre la terminología institucional: "violencia de género".

\subsubsection{Televisión Española: en primer lugar el agresor}

Es la única de las noticias analizadas que no se anticipa en titulares, sino que aparece directamente en el minuto 18:53 del informativo. Es una información tipo 'colas' que dura 1:14 minutos y está situada entre una noticia política y una información internacional. Así, puede decirse que esta pieza está encuadrada dentro de la parte "dura" del informativo, aunque no esté anticipada en titulares.

Está compuesta, una vez más, por imágenes propias que esta vez "bajan la intensidad" de su dramatismo. Son menos "sangrientas" tanto por el contenido (hay muchos menos lamentos de familiares y amigos, así como de restos de sangre) como por el tiempo de aparición de los escasos elementos dramáticos (sólo en un plano vemos sangre, y además éste dura poco más de dos segundos). Se centra más bien en los equipos de trabajadores como la Ertzaintza o los forenses, y en las concentraciones de repulsa. Asimismo, observamos por primera vez imágenes que no corresponden a la escena del suceso: una manifestación de rechazo frente a las puertas de un ayuntamiento para condenar la muerte de una mujer cuyo asesinato está aún investigándose $\mathrm{y}$ al que se hace referencia en el texto.

Además, en la pieza de TVE no se incluyen testimonios y priman los planos semánticos (donde la sangre servía de imagen ilustrativa en las anteriores noticias, aquí 
se convierte en metáfora de lo relatado). Sigue, como la anterior, una secuencialidad de tipo lógico. En cuanto a las cuestiones formales, encontramos planos más generales para contextualizar los hechos y panorámicas sobre trípode que, junto a la inclusión de imágenes más allá del caso concreto de violencia de género en Barakaldo, nos dan la sensación de estar frente a una noticia elaborada de manera más pausada y meditada.

Se trata nuevamente de una noticia "dura", "simple" (aunque se menciona a otra víctima en Alicante, es un dato que no tiene el suficiente peso como para evitar la hegemonía temática de la muerte de la mujer de Barakaldo) y "de interés humano". Está ilustrada con imágenes, pero de una manera no tan clara como en las ocasiones anteriores. Es decir, atendiendo sólo a las imágenes, podría tratarse del escenario de cualquier suceso violento, ya que éstas no apuntan a elementos visualmente identificativos o específicos.

El tono es serio, pero sobre todo, habitual. La presentadora no imprime ningún tipo de emoción a la locución, sino que opta por un estilo natural. El tipo de verbos utilizados muestra un grado de intensidad bajo si los comparamos con las piezas anteriormente analizadas ("muerte" en lugar de "asesinato", "agredido" en lugar de "malherido", "herido por arma blanca" en lugar de "apuñalado", etc.). Además, ya no apreciamos personalizaciones sino que la información se relata de manera aséptica, distanciada, y la víctima deja de tener un papel central.

La estructura de la información es la siguiente:

- [Plató: introducción presentadora]: Comienza el relato con la figura del agresor: "Un joven de 25 años ha sido detenido en Barakaldo, en Vizcaya, acusado de la muerte de su ex pareja".

- [Colas] Aparece en este momento el titular: "Tenía orden de alejamiento. Un joven detenido por la muerte de su pareja en Barakaldo".

- Se explicita que en el momento de la agresión a ella la acompañaba su actual pareja y que ambos fueron heridos con un arma blanca.

- Aparece un rótulo: "Teléfono contra el maltrato 016".

- Se dice que sobre el agresor pesaba una orden de alejamiento y que de confirmarse éste y el caso de otra mujer en Alicante, estaríamos ante la víctima 67 en lo que va de año.

El foco de la información se sitúa en la figura del agresor, y esto lo deducimos por la importancia que se concede al sujeto actante y por las continuas referencias a éste a lo largo de la pieza. En la noticia no se hace hincapié en ningún detalle sobre la muerte de la víctima, sobre cómo se sucedieron los hechos o sobre la ineficacia de las medidas de protección; por el contrario, nos llama la atención la centralidad del sujeto agresor, cosa que puede verse en el siguiente esquema de cómo se organiza la pieza:

a) Un hombre agrede a dos personas: su ex novia y el actual novio de ésta.

b) El hombre tenía una orden de alejamiento.

c) El hombre puede haber causado la víctima número 67 en lo que va de año.

Por lo que respecta a la terminología, se utilizan las expresiones "violencia machista" y "maltrato". Aunque no nos sentimos en disposición de realizar una valora- 
ción profunda sobre la diferencia y pertinencia de los términos utilizados, sí que podemos reseñar que el primero de ellos recoge un campo de manifestaciones mayor al que puede incluirse bajo la denominación de "maltrato", que usualmente se usa en el terreno periodístico como sinónimo de "paliza", según las investigaciones que hemos realizado en este terreno hasta el momento.

Podemos concluir el análisis señalando que se trata de una pieza con alto valor informativo, aunque quizá algo escueta, ya que se omiten ciertos datos importantes que sí que aparecían en las noticias anteriores, además de faltar -como en el resto- consultas a expertos y una profundización en los porqués de esta lacra social y de este caso en particular.

\subsubsection{Canal Sur: escueto e impersonal}

Aquí, nuevamente la noticia se anticipa en titulares (minuto 5:25) tras una ráfaga bajo el rótulo "Violencia machista". Se trata de unas colas que nos muestran el lugar de los hechos en planos generales (aparecen bloques de pisos, se puede identificar un barrio). El relato dura trece segundos en los que se nos dice que un joven ha sido detenido y que tenía una orden de alejamiento por amenazas. En cuanto a la terminología, se opta por "violencia machista". Además, tenemos un dato que desconocíamos hasta este momento: la denuncia ha sido por amenazas.

La pieza se sitúa en el minuto 35:34 del informativo, entre una noticia política de carácter general y la petición de ayuda a la comunidad internacional por parte de la Consejería de Igualdad y Bienestar Social para la lucha contra el tráfico de menores. Predominan también las imágenes propias, pero en este caso son "imágenes-recurso". Aparecen básicamente tres espacios sobre los que se realizan varias panorámicas: un banco de madera con manchas de sangre, un edificio (presumiblemente en el que acontecieron los hechos) y un plano del portal del edificio anterior. Es decir, en todas las imágenes lo que vemos es una localización: un barrio, un bloque, la puerta de un edificio..., pero no elementos que puedan relacionarse directamente con la víctima (excepto en el caso de la sangre).

La secuencialidad vuelve a ser de tipo lógico. Nos encontramos frente a una noticia "hard" construida mediante imágenes ilustrativas pero sin relación directa con el asunto relatado (a excepción, nuevamente, de los planos con restos de sangre). El tono del periodista es serio y en ningún momento pone un énfasis especial ni realiza entonaciones dramatizadas.

La estructura de la información es la siguiente:

- [Plató: introducción del presentador] La narración se inicia de este modo: "En Barakaldo, Vizcaya, una joven de 25 años ha sido asesinada presuntamente por su ex pareja, quien al parecer también ha herido de gravedad al actual compañero de la mujer..."

- [Colas] Aparece el titular: "Asesinada por su exnovio en Baracaldo (sic). Contra la violencia machista 900200 999".

- Se cuenta que la mujer agredida falleció en el lugar de los hechos, que el autor está detenido y que el agresor tenía antecedentes y una orden de alejamiento.

- La información se cubre con las imágenes de recurso ya descritas. 
El foco de atención de la información no es muy evidente, dada la escasa duración de la pieza. En este sentido, únicamente da tiempo a señalar los datos estrictamente necesarios y la noticia se centra en ningún elemento de manera especial. Los rótulos, sin embargo, parecen inclinar la balanza hacia la protección, ya que además de dar el titular principal, muestran el número de atención a las víctimas. No obstante, éste no es el 016, sino el del servicio equivalente de la Junta de Andalucía. Por otra parte, el emisor principal vuelve a ser aquí el presentador, ya que no tenemos un VTR sino una información en forma de 'colas'.

En resumen, podemos decir que a pesar de que la pieza cumple con los criterios de noticiabilidad (actualidad, proximidad, relevancia social de la información, etc.), volvemos a encontrar una falta de contextualización y de consulta a fuentes expertas. Pero en este caso, además, no se dan datos básicos que sí que se ofrecen en otras cadenas (aunque esto se explica principalmente por la escasa duración de esta pieza). Así, aunque el resto de noticias tampoco cumplan totalmente estos criterios, gracias a otros recursos como una mayor duración, la variedad en las fuentes, etc., este hecho queda matizado en cierta manera, lo cual no quiere decir que el enfoque que siguen deje de ser "episódico" y de sucesos (Carballido González, 2009). Sin embargo, en el caso de Canal Sur, la pieza podría considerarse más claramente como una noticia de sucesos:

Estas son las noticias que apenas rozan el medio minuto de duración, y en las que las imágenes que recurrentemente se ofrecen son las que corresponderían a cualquier suceso y que se reducen, generalmente, al domicilio de la víctima, con planos detalle de porteros automáticos, manchas de sangre, descampados y, en ocasiones imágenes de algún hospital (IORTVE 2002).

\subsubsection{Apuntes finales sobre el análisis}

A continuación, resumimos algunos de los puntos centrales del análisis en busca de una imagen clara y comparativa del tratamiento de diversos elementos por parte de las cadenas estudiadas, y posteriormente analizaremos el seguimiento de los códigos de autorregulación.

En cuanto al formato de las piezas, éste depende estrechamente del tiempo otorgado, que es también un indicador de la importancia concedida a la noticia, siendo las que disponen de más tiempo las piezas más complejas. El formato también tiene que ver con cierto dramatismo dado por la configuración noticiosa, pero el valor que prevalece es, por regla general, el informativo.

Con respecto al foco de atención, destacamos que principalmente lo constituye la agresión física a la víctima y, en segundo lugar, la ineficacia de las medidas legales o el hecho de que el agresor contase con una orden de alejamiento.

\begin{tabular}{|c|c|c|c|c|}
\hline \multicolumn{4}{|c|}{ Cuadro 2: Focalización informativa } \\
\hline Cadena emisión & T5 & Cuatro & TVE & CanalSur \\
\hline Foco informativo & $\begin{array}{c}\text { Ineficacia } \\
\text { medidas }\end{array}$ & $\begin{array}{c}\text { Ineficacia } \\
\text { medidas }\end{array}$ & Agresor & Protección \\
\hline
\end{tabular}

En el caso de Televisión Española y Canal Sur, sin embargo, la cuestión del foco informativo no está clara, ya que dada la escasa duración de las respectivas piezas, sólo se vierten los datos esenciales sin reparar especialmente en ningún aspecto. Aunque 
por lo que se refiere a la cadena estatal, nos inclinamos por la idea de que el núcleo informativo lo constituye el agresor, debido a la importancia de esta figura como sujeto de las enunciaciones informativas, al hilo de lo que recomienda el Manual de Urgencia (2002):

El lenguaje es un mecanismo fundamental que influye en la percepción social de los asuntos públicos y por ello sería muy recomendable que el relato de la acción recayera sobre el sujeto activo, es decir, el maltratador, homicida o asesino y no sobre el sujeto pasivo, la víctima.

Con respecto a la forma de conceptualización, tenemos que decir que ninguna noticia parece abandonar el encuadre episódico ya que todas se centran en la agresión en sí, y sólo en los casos de Cuatro y TVE se procede a ciertos visos de contextualización. $\mathrm{O}$, dicho de otro modo, la violencia de género en la televisión viene a ser el relato de cómo los hombres matan a las mujeres. En cambio, no es así como hay que tratar en los medios esta lacra social:

No es una noticia convencional [...] Si su inclusión en el informativo o sección no responde a una valoración informativa adecuada, el resultado puede ser pernicioso. Hay que dejar claro que los malos tratos son un problema social, y que la violencia contra las mujeres constituye un atentado contra el derecho a la vida, la dignidad y la integridad física y psíquica de las víctimas; en definitiva, un atentado contra ellas y contra sus derechos humanos [...] Los malos tratos son un delito cuyo origen está en la consideración de inferioridad de las mujeres, y no se puede presentar como un crimen pasional [...] deben ubicarse en las secciones de sociedad, y nunca como sucesos (Instituto Oficial de Radio y Televisión, 2002).

A un correcto tratamiento mediático de la violencia de género no ayuda precisamente el caos terminológico que encontramos en nuestra actualidad informativa, máxime cuando algunas de las recomendaciones que se hacen de forma institucional no están en línea con las concepciones generalmente asumidas (evitamos utilizar de forma consciente el término "consenso"):

Aunque no hay un consenso en esta cuestión, se ha difundido de manera bastante generalizada la calificación "violencia de género" [...] No obstante, y dado que se trata de comunicar, el término "violencia de género" no resulta claro para el público. Será aconsejable, cuando se utilice, acompañarlo de expresiones como "violencia contra las mujeres en el ámbito doméstico", "violencia masculina en la familia" o "violencia contra las mujeres" en general que facilitan la comprensión de la noticia (IORTVE, 2002).

Autoras de otros ámbitos sí que se muestran favorables al concepto "género", o rechazan otros términos por considerarlos imprecisos o erróneos:

La perspectiva de género permite a la vez tener en cuenta a las mujeres y a los hombres en la sociedad y superar el victimismo y el revanchismo en que tan frecuentemente, aunque fuera con razón, había caído el pensamiento feminista (Alberdi, I., 2007:15).

The terms family violence and domestic violence will not be used to denote battering because these terms obscure the relationship between gender and power by failing to identify the perpetrators and victims. In fact, in $95 \%$ of the cases of domestic or family violence, the victims are women and de aggressors are men (Meyers, M., 1997:7) 


\begin{tabular}{|c|c|c|c|c|}
\hline \multicolumn{4}{|c|}{ Cuadro 3: Fórmulas terminológicas de referencia } \\
\hline Cadena emisión & T5 & Cuatro & TVE & CanalSur \\
\hline $\begin{array}{c}\text { Terminología } \\
\text { empleada }\end{array}$ & $\begin{array}{c}\text { V. machista } \\
\text { V. doméstica }\end{array}$ & V. de género & $\begin{array}{c}\text { V. machista } \\
\text { Maltrato }\end{array}$ & V. machista \\
\hline
\end{tabular}

\subsection{El seguimiento de las recomendaciones}

Lejos de pretender realizar aquí una evaluación de la praxis periodística, sí que podemos considerar este apartado como una revisión de la habitualidad televisiva tras las diversas recomendaciones deontológicas existentes en nuestro contexto. Para ello y como decíamos en el planteamiento, hemos tomado como referencia principal el $\mathrm{Ma}$ nual de Urgencia sobre el tratamiento de la violencia contra las mujeres de 2002.

Uno de los puntos de este decálogo hace alusión a los modelos femeninos que lesionan la dignidad de la propia mujer. En este sentido y a pesar de que en un estudio de caso no tiene sentido hablar de modelos, sí que podemos destacar que aunque no se reproduzcan estereotipos, la centralidad informativa con respecto a los sujetos implicados es preponderantemente femenina y ligada a la esfera de la víctima, a la cual se compadece, cosa que redunda en una doble victimización de la mujer: como víctima directa y como víctima en el discurso periodístico.

En este sentido puede reseñarse también que ninguno de los enfoques noticiosos aborda este problema como un atentado contra los derechos humanos. En el mejor de los casos, existe una cierta contextualización nacional (número de víctima que ocupa la mujer de cuyo asesinato se informa). El tratamiento noticioso que se le da no está alejado de lo que podemos llamar "tratamiento tipo"" o, lo que es lo mismo: descontextualizado, simplista y fácil, del cual se pretende huir (punto 4 del decálogo referido). Ninguno de los casos analizados responde a los preceptos de investigación, detenimiento, contextualización y reflexión expuestos en el Manual. Es cierto que uno de los preceptos de los informativos televisivos es la urgencia, pero es precisamente en este sentido en el que se pretenden realizar cambios, si bien es cierto que supondría un esfuerzo ingente destinado a modificar concepciones editoriales e incluso de la propia ciudadanía, ya que un correcto tratamiento antepondría calidad a actualidad, lo que impediría en algunos casos informar del hecho en el momento en el que éste se produce.

Esto tiene mucho que ver con no confundir el morbo con el interés social. Aunque en este punto el Manual hace referencia únicamente a testimonios de víctimas ("una víctima de malos tratos puede ser un buen testimonio, pero nunca un gancho publicitario. El infoespectáculo no es el formato adecuado para este tipo de violencia", Instituto Oficial de Radio y Televisión, 2002), podemos aprovecharlo para exponer nuestras dudas sobre la pertinencia del testimonio que abre la pieza informativa de la cadena Cuatro. Dicho testimonio es una declaración de una de las amigas de la víctima antes de saber que ha fallecido. Sus palabras no aportan nada significativo, ni si-

7 Ir al lugar de los hechos para contarlos en directo a ser posible, y si no, grabar los restos del suceso e incluir testimonios de testigos o de personas cercanas a los protagonistas de la noticia. 
quiera se ciñen al problema: "No, yo soy amiga de ella. No sé, me acaban de llamar los colegas que eso que el chaval, el ex novio, que no saben nada de él desde anoche". Lo cual lleva inexorablemente a la evaluación de la pertinencia de las fuentes informativas (punto 5). En los casos analizados se aprecia una falta absoluta de expertos. Las fuentes predominantes en nuestro estudio son femeninas, no están identificadas y pertenecen al entorno de la víctima.

Con este uso de las fuentes "dar información útil, asesorarse previamente" (punto 6) se torna más complicado y la información que llega a la ciudadanía es la que espontáneamente ofrecen personas afectadas emocionalmente. De nuevo denunciamos aquí la falta de fuentes expertas que contextualicen, expliquen y aporten otros datos y enfoques pertinentes. En cuanto a la información útil, hay un acuerdo mediático sobre la indicación del teléfono contra los malos tratos (016), aunque hemos de recordar que Canal Sur da el número autonómico en lugar del genérico.

Otra de las claves en las que se incide deontológicamente es en la identificación: hay que proteger a la víctima (su dignidad, su honor, su intimidad y la de sus familiares), así como identificar claramente al agresor. En este punto volvemos a destacar el tratamiento que hace $T V E$, que introduce la noticia con la figura del agresor como responsable de una muerte, a diferencia de las otras cadenas que destacan una nueva muerte. Este dato es importante ya que normalmente el centro de la noticia suele ser la víctima, el dolor, la injusticia y la desgracia, más que la autoría y la responsabilidad.

En cuanto al uso de las imágenes, lejos de buscarse imágenes recurso o de archivo con las que cubrir la información, se sigue prefiriendo acudir al lugar de los hechos para grabar los restos de la agresión, así como la actitud doliente del entorno de la víctima. Esto refuerza el papel de víctima de la mujer y, según perspectivas feministas, favorece la idea de que las mujeres son "menores de edad", sujetos a los que proteger y cuidar.

El último de los aspectos que merece la pena reseñar es la cuestión de las cifras que pueden servir tanto como recurso retórico y práctica de lo políticamente correcto, como de verdadera fuente de información y excusa para explicaciones e implicaciones. "Los datos hacen referencia a distintos tipos de violencia y a distintos ámbitos territoriales: víctimas fuera de una relación de pareja, víctimas que pierden la vida tras un periodo de convalecencia y suicidios provocados por los malos tratos que sólo cuentan como suicidios" (Instituto Oficial de Radio y Televisión, 2002). En este sentido, cabe destacar que la mayoría de noticias analizadas se centra en las víctimas concretas y que, en caso de dar datos más generales, éstos se ciñen al número de víctimas mortales al año y al porcentaje de éstas que había denunciado previamente. Parece, por tanto, que falta contextualización numérica.

\section{Discusión y conclusiones}

El análisis de la cobertura informativa del asesinato de la mujer de Barakaldo revela un tratamiento realizado a medias desde la conciencia de la relevancia del problema y a medias desde las lógicas productivas imperantes. Por un lado, se aprecia cómo determinados consensos informativos han calado hondo, como el acuerdo de visibilizar siempre el número de atención a las víctimas, sin embargo, también se mantienen los 
excesos amarillistas sustentados en los criterios de mercado: rapidez, rentabilidad, impacto, beneficio. Aunque el trabajo realizado permite vislumbrar esfuerzos considerables en la lucha contra los estereotipos y prejuicios, aún tenemos que lamentar la doble victimización de la mujer que por un lado sufre la agresión del hombre, y por otro, la del discurso que la relega a ser una víctima siempre y en todas las circunstancias.

A las mujeres solo les queda ser víctimas arquetípicas del control masculino, seres "sexualmente oprimidos" y convertidos en "objetos que se definen", frente a los hombres, que son los "sujetos que ejercen violencia". De esta manera, la sociedad queda dividida en dos grupos, 'los que detentan el poder (hombres) y las que carecen de poder (mujeres) (Mohanty, 2008: 123, 124).

Por otro lado, también queremos insistir en la necesidad de abandonar los tintes sensacionalistas que todavía encontramos fácilmente en las informaciones sobre violencia de género. En este sentido, creemos que determinados testimonios con gran carga dramática y la abundante utilización de imágenes que muestran los restos de las agresiones sirven más para explotar el morbo de los hechos concretos que para concienciar sobre el problema global de la violencia contra las mujeres.

El relato televisivo de la violencia de género es todavía un relato circunscrito al ámbito de las agresiones y los sucesos. A pesar de la conciencia generalizada de que es necesario adoptar un modelo distinto al habitual ${ }^{8}$, la televisión sigue manteniendo su rígido formato basado en la imagen, la inmediatez y los detalles. Estamos ante un tipo de información donde prima la falta contexto y donde se abusa de las imágenes de sangre y de los testimonios no expertos que sólo ofrecen su experiencia particular de los hechos. En consecuencia, tenemos la impresión de que ni siquiera una muerte funciona de acicate para hablar de violencia de género, de qué es ésta más allá de la muerte concreta sobre la que se informa, de cómo afecta a todas las mujeres y a lo largo de la Historia, de qué piensan los expertos de la situación actual, de qué medidas existen para frenar este problema y de cuáles están fallando?.

En definitiva, creemos que los informativos deberían hablar de la violencia contra las mujeres y no de la muerte de una mujer a manos de su pareja. De este modo, violencia de género, ese rótulo informativo, acaba convirtiéndose en un relato simplista y descontextualizado sobre "cómo los hombres matan a sus esposas"10. Pero si de algo tenemos que lamentarnos todavía hoy, es precisamente de esa reticencia a tratar la violencia de género como el problema estructural y social que es. La labor de los medios de comunicación no pasa -o no debería pasar- sólo por informar de los casos concretos. Los media han de fomentar el conocimiento y la sensibilidad social sobre este asunto y para ello no deben circunscribirse a una de las manifestaciones de dicha violencia (la violencia de pareja), sino dar cabida al compendio de todos los tipos posi-

8 El $60 \%$ de los españoles considera poco objetivo y sensacionalista el tratamiento que los medios de comunicación dan a la violencia de género (Fernández y Noblejas, 2010).

9 En este sentido, tenemos que aplaudir el interés en las noticias analizadas por las medidas que no están resultando eficaces

${ }^{10}$ Sobre la cuestión de la conceptualización del fenómeno puede consultarse: Zurbano, 2010. 
bles de opresión de la mujer, teniendo en cuenta además que la violencia física rara vez está exenta de violencia psicológica o que todavía la agresión sexual y el miedo que genera actúan como coercitivo social femenino.

En este sentido aludíamos en nuestro análisis a la falta de los "porqués", de las causas de la violencia contra las mujeres. Con esto no nos referíamos a las especulaciones del los periodistas sobre las razones de un crimen concreto, sino a la necesidad de una correcta contextualización y a la consulta de fuentes expertas. Asimismo, en la lucha contra un enfoque de la información sobre violencia de género que en muchas ocasiones se parece demasiado al de las noticias de sucesos, tienen gran importancia la terminología como síntoma, y el formato como consecuencia.

Si damos por aceptada la idea de que los medios de comunicación hacen suya la lucha común contra la lacra de la violencia de género, ciertas desviaciones como las que este artículo pone de manifiesto no debe sino contribuir a la reflexión serena sobre las causas de las mismas: ¿Falta de tiempo? ¿Necesidad de mostrar lo que otros muestran? ¿Falta de formación? ¿Rigidez de los formatos? ¿Rigidez mental de quienes perpetúan dichos formatos? La información vertida por los media y el contenido de los códigos deontológicos o decálogos para las buenas prácticas, en ocasiones, como hemos podido comprobar, no coinciden, lo que despierta ciertas dudas en cuanto a la configuración de los procesos periodísticos en nuestro entorno y en cuanto a la finalidad de los mismos.

\section{Referencias}

AA.VV. (2005): Manual de géneros periodísticos. Bogotá, ECOE.

BARDIN, Laurence (1986): Análisis de contenido. Madrid, Akal.

BOLETÍN OFICIAL DEL ESTADO (2004): Ley Orgánica 1/2004, de 28 de diciembre, de Medidas de Protección Integral contra la Violencia de Género. BOE, 29 de diciembre de 2004, núm. 313.

ESTUDIO GENERAL DE MEDIOS (2011): "Primera ola de 2011: abril 2010 a marzo 2011": http://www.aimc.es/Entrega-de-resultados-EGM-1\%C2\%AA-ola.html [fecha de consulta: 11 de abril de 2011].

FERNÁNDEZ Y NOBLEJAS (2011): Cómo informar sobre violencia contra la mujer en las relaciones de pareja. España, Escuela de Periodismo y Comunicación, p. 239.

INSTITUTO OFICIAL DE RADIO Y TELEVISIÓN (2002): Manual de urgencia. Cuestión de principios. Mujer, violencia y medios de comunicación: http://estaticos.elmundo.es/documentos/2004/06/sociedad/malostratos/mujer_violencia_ymedios.pdf [fecha de consulta: 11 de febrero de 2011].

KRIPPENDORFF, Klaus (1990): Metodología de análisis de contenido. Teoría y práctica. Barcelona, Paidós.

LORENTE ACOSTA, Miguel (2009): “¿Qué papel pueden tener los medios de comunicación de masas en la erradicación de la violencia de género al amparo de la 
Ley Integral?", en BERNARDO PANIAGUA, José María (coord.): Retos de la Comunicación ante la Violencia de género. Marco jurídico, discurso mediático y compromiso social. Barcelona, Tirant Lo Blanch, pp. 49-63.

MINISTERIO DE SANIDAD, POLÍTICA SOCIAL E IGUALDAD (2011): "Encuesta de opinión sobre la violencia de género" http://www.msps.es/gabinetePrensa/notaPrensa/desarrolloNotaPrensa.jsp?id=2176 $>$ [fecha de consulta 1 de abril de 2012].

SANMARTÍN ESPLUGUES, José et al. (2010): III Informe Internacional. Violencia contra la mujer en las relaciones de pareja (estadísticas y legislación). Valencia, Centro Reina Sofía.

TALPADE MOHANTY, Chandra (2008): "Bajo los ojos de Occidente. Academia Feminista y discurso colonial”, en SUAREZ, Liliana y HERNÁNDEZ, Rosalva Aída: Descolonizando el feminismo. Teorías y prácticas desde los márgenes. Madrid, Cátedra, pp. 112-161.

VEGA MONTIEL, Aimée (2010): "La responsabilidad de la televisión mexicana en la erradicación de la violencia de género contra las mujeres y las niñas: apuntes de una investigación diagnóstica". Nueva época, núm. 13, enero-junio, pp. 43-68.

VIVES CASES, Carmen et al. (2009): "The effect of television news items on intimate partner violence murders". European Journal of Public Health, Vol. 19, No. 6.

ZURBANO BERENGUER, Belén (2010): "Más allá del crimen y el suceso: la violencia de género en la prensa española", en MANCINAS CHÁVEZ, Rosalba y NOGALES BOCIO, Antonia Isabel (Coords.): La mujer en el espejo mediático. El mediotrato femenino. Sevilla, Asociación Universitaria Comunicación y Cultura (AUCC), Grupo de Investigación en Estructura, Historia y Contenidos de la Comunicación (GREHCCO). 